\title{
A comparative study between conventional nasal packing versus nasal splint with clip after septoplasty with bilateral reduction of inferior turbinates with bipolar cautery
}

\author{
Santosh Uttarkar Pandurangarao*, Mallikarjunappa Ajjampura Murugendrappa, \\ Dheeraj Kumar Jonnalagadda, Raga Panicker, Sridurga Janarthanan
}

Department of ENT, JJM Medical College, Davangere, Karnataka, India

Received: 09 April 2018

Revised: 27 April 2018

Accepted: 28 April 2018

*Correspondence:

Dr. Santosh Uttarkar Pandurangarao,

E-mail: drsantoshup@gmail.com

Copyright: (C) the author(s), publisher and licensee Medip Academy. This is an open-access article distributed under the terms of the Creative Commons Attribution Non-Commercial License, which permits unrestricted non-commercial use, distribution, and reproduction in any medium, provided the original work is properly cited.

\begin{abstract}
Background: Nasal packing is an important step after septal surgeries. Conventional nasal packing with vaseline gauze is associated with significant morbidity. Of late, the nasal splint with clip has been tried as an alternative in an attempt to prevent this morbidity. The aim of our study is to compare post-operative morbidities of conventional nasal packing (using vaseline gauze) and nasal splint with clip following septoplasty and cauterization of inferior turbinates. Methods: A comparative study was conducted on 50 patients who underwent septoplasty surgery with reduction of both inferior turbinates using bipolar cautery. In the postoperative period, patients were assessed for pain, nasal obstruction, head ache and ear complaints.

Results: Patients in whom nasal splint with clip were used, were found to have a more comfortable postoperative period when compared to conventional nasal packing, which was found to be statistically significant.

Conclusions: Post-operative morbidity has been found to be significantly lower with nasal splint with clip in comparison to conventional nasal packing using vaseline gauze.
\end{abstract}

Keywords: Nasal splints, Turbinates, Cautery, Septal correction, Septoplasty

\section{INTRODUCTION}

Surgeries for correction of the deviated nasal septum are some of the most commonly performed surgeries by otorhinolaryngologists. Nasal packing following septal correction is being followed since the advent of these surgeries, to prevent post-operative epistaxis and formation of hematoma and synechiae. Conventional nasal packing uses ribbon gauze with paraffin (Vaseline gauze) and is associated with significant discomfort to the patient due to complete blockage of nasal airflow, causing nasal obstruction, headache, pain and sometimes serious complications like toxic shock syndrome, vasovagal attack, hypoxemia and its sequelae. In addition, pack removal is associated with pain. Nasal splints have been introduced as an alternative to nasal packing, and can effectively prevent bleeding, hematoma and synechiae formation, without the above mentioned morbidities.

Other commonly used materials for nasal packing include ribbon gauze with antibiotic ointment, BIPP (Bismuth Iodoform Paraffin Pack), glove finger pack, Telfa and Merocel nasal packs (varieties of absorbant, non adherent anterior nasal packs). ${ }^{1}$

Intranasal splints have evolved over time from 1955, when it was first introduced by Salinger and Cohen, who 
used easily available material like $\mathrm{X}$ ray film and were held in place by septal suturing. ${ }^{2}$ Goode, in 1980s introduced magnetic intranasal splints, which hold the flaps in place by magnetic attraction. ${ }^{3}$ Following this, many modified splints were fashioned including wax plates, silicon and silastic sheets, but all required septal suturing. ${ }^{4}$

In addition to septal deviation, many patients have co existent hypertrophy of inferior turbinates which contribute to nasal obstruction. For improved outcome, management of turbinate hypertrophy is also important. Various methods in use for turbinate reduction are out fracture of turbinate, turbinoplasty, cauterization of turbinate, laser resection and radiofrequency ablation to name a few.

In our study, we compared nasal packing using Vaseline gauze with septal splints with clip in patients who underwent septoplasty with inferior turbinate reduction by bipolar cauterization.

\section{METHODS}

This is a prospective, comparative, randomized study conducted on patients who were operated in a tertiary care centre in central Karnataka between September 2016 and December 2017. After institutional ethical committee clearance, 50 patients between 18 and 50 years of age, belonging to either gender, were randomly selected for the study, and underwent septoplasty, with bipolar cauterization of inferior turbinates under general anaesthesia. Patients who had associated nasal polyposis, chronic sinusitis and other conditions that necessitated endoscopic sinus surgery, and patients below 18years and over 50 years of age were excluded from the study.

Informed, written consent was obtained from all patients and a note was made of patient demographics. The patients were arbitrarily divided into two groups - Group A (25 patients) underwent nasal packing using Vaseline gauze and Group B (25 patients) were managed using septal splints with clips. Assessment of morbidity was done at 8 hours after surgery and at the time of pack removal (24 hours post-surgery). Pain was graded using visual analogue scale from 1 to 10 . Headache, nasal obstruction and ear symptoms such as ear blocking sensation are the other factors which were assessed. Statistical analysis was done using SPSS Software.

Description of procedure: Septoplasty was done as was required according to the type of septal deviation. Following this, under proper visualization, inferior turbinates on both sides were reduced using bipolar cautery in all cases.

Group A - At the end of septoplasty, both nasal cavities were packed with Vaseline ribbon gauze using Tilley's nasal dressing forceps under visualization using Killian's nasal speculum. A sterile gauze dressing was given which was supported by adhesive tapes.

Group B - Internal nasal splints made of polythene (made available from the manufacturer) were used, one in each nasal cavity, and secured at its anterior end using stainless steel clips with a spring action. In order to prevent posterior migration, the anterior ends were tied together using a cotton thread passed through both the splints, but without suturing over the septum. (Figure 1).

\section{RESULTS}

The demographic details like age and sex distribution of the patients are given in the following table (Table 1).

Table 1: Age and sex distribution.

\begin{tabular}{|llll|}
\hline Age (years) & Number of cases & Males & Females \\
\hline $\mathbf{1 8 - 2 5}$ & 17 & 7 & 10 \\
\hline $\mathbf{2 6 - 4 0}$ & 20 & 8 & 12 \\
\hline $\mathbf{4 1 - 5 6}$ & 13 & 5 & 8 \\
\hline
\end{tabular}

Table 2: Side of deviation.

\begin{tabular}{|lll|}
\hline No of cases & $\begin{array}{l}\text { Deviated nasal } \\
\text { septum to right } \\
\text { side }\end{array}$ & $\begin{array}{l}\text { Deviated nasal } \\
\text { septum to left } \\
\text { side }\end{array}$ \\
\hline Group A (25) & 18 & 7 \\
\hline Group B (25) & 16 & 9 \\
\hline
\end{tabular}

Out of 50 patient, in Group A 18 patients had deviation of nasal septum to right side and 7 patients had deviation to left side, in Group B 16 patients had deviation of nasal septum to right side and 9 patients to left side (Table 2).

All the patients had grade 2 or grade 3 hypertrophy of inferior turbinates and there was no significant difference between turbinate hypertrophy grading between the 2 groups.

For all 50 patients, pain, headache and nasal obstruction were calculated by visual analogue score at $8 \mathrm{hrs}$ and 24 hrs (After pack removal) postoperatively.

The mean postoperative pain score at $8 \mathrm{hrs}$ for Group A was 7.44 and for Group B was 2.2, mean postoperative pain score at $24 \mathrm{hrs}$ (after pack removal) for Group A was 6.08 and for Group B was 1.92 and p value was $(<0.01)$ (Table 3).

The VAS for headache and nasal obstruction were calculated and were significant with $\mathrm{p}$ value $(<0.01)$ (Table 4 and 5).

Various symptoms like ear block, epiphora and sleep discomfort were higher in patients in Group A (Pack) compared to patients in Group B (Splint) (Table 6). 
Table 3: Visual analogue score for pain.

\begin{tabular}{|lllllllllll|l|}
\hline Pain & 1 & 2 & 3 & 4 & 5 & 6 & 7 & 8 & 9 & 10 \\
\hline Group A (8 hrs) & 0 & 0 & 0 & 2 & 3 & 3 & 4 & 4 & 5 & 4 \\
\hline Group B (8 hrs) & 10 & 5 & 4 & 3 & 1 & 1 & 1 & 0 & 0 & 0 \\
\hline Group A (12 hrs) & 0 & 2 & 3 & 2 & 5 & 4 & 6 & 2 & 2 & 0 \\
\hline Group B (12 hrs) & 12 & 4 & 2 & 3 & 2 & 2 & 0 & 0 & 0 & 0 \\
\hline
\end{tabular}

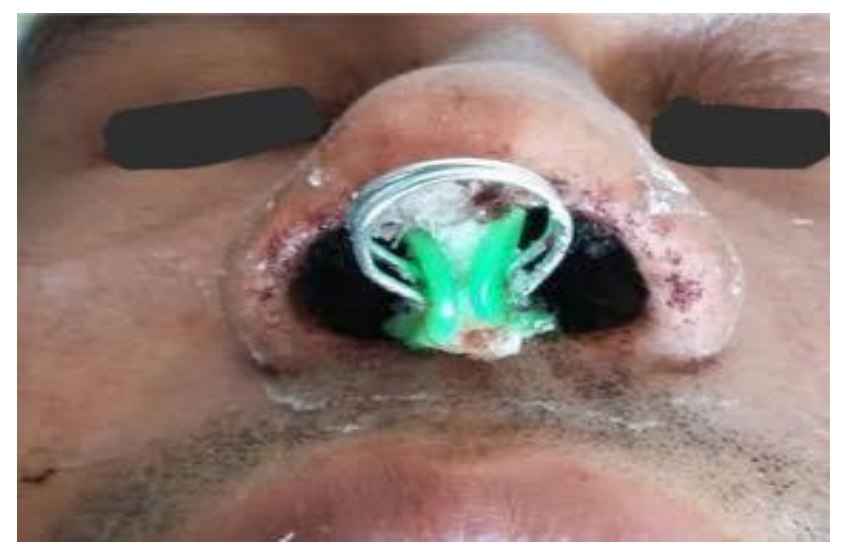

Figure 1: Intranasal splint with clip in place.

Table 4: Visual analogue score for headache.

\begin{tabular}{|lll|}
\hline Headache (VAS) & $<\mathbf{5}$ & $>\mathbf{5}$ \\
\hline Group A (8 hr) & 7 & 18 \\
\hline Group B (8 hr) & 19 & 6 \\
\hline Group A (12 hr) & 15 & 10 \\
\hline Group B (12 hr) & 22 & 3 \\
\hline
\end{tabular}

Table 5: Visual analogue score for nasal obstruction.

\begin{tabular}{|lll|}
\hline Nasal obstruction (VAS) & $<\mathbf{5}$ & $>\mathbf{5}$ \\
\hline Group A (8 hr) & 0 & 25 \\
\hline Group B (8 hr) & 20 & 5 \\
\hline Group A (24 hr) & 7 & 18 \\
\hline Group B (24 hr) & 23 & 2 \\
\hline
\end{tabular}

Table 6: Comparison of various symptoms.

\begin{tabular}{|llll|}
\hline Symptom & Group A & Group B & P value \\
\hline Ear block & $19(76 \%)$ & $3(12 \%)$ & $<0.01$ \\
\hline Epiphora & $23(92 \%)$ & $4(16 \%)$ & $<0.01$ \\
\hline Sleep discomfort & $20(80 \%)$ & $5(20 \%)$ & $<0.01$ \\
\hline
\end{tabular}

Table 7: Mean time consumption.

\begin{tabular}{|c|c|c|c|}
\hline Intraoperative & Group A & Group B & P value \\
\hline $\begin{array}{l}\text { Mean time } \\
\text { consumption for } \\
\text { pack or splint } \\
\text { placement (in } \\
\text { minutes) }\end{array}$ & $3.45 \pm 1$ & $2.2 \pm 0.40$ & $<0.01$ \\
\hline
\end{tabular}

The mean time consumption is calculated for nasal packing procedures done in Group A and splint application with clips in Group B. Nasal splint with clips had less time consumption (Table 7).

\section{DISCUSSION}

All the previous studies on nasal splints with clips were done on patients undergoing nasal septal surgeries. This is a unique study in which nasal septal surgeries along with reduction of inferior turbinate using bipolar cautery was done.

The conventional method of managing patients following septal surgeries involve packing both nasal cavities using various materials in an air tight fashion, which comes with its share of discomfort and complications. Nasal packing is done to control nasal hemorrhage, prevent septal hematoma or to prevent synechiae formation in the long term. ${ }^{5}$ Different packing materials have been tried in an effort to reduce the undesirable effects and to improve patient comfort in immediate post-operative period, of which nasal splint with clip is one of the emerging modalities.

Veluswamy et al, in their study has observed that septal splints with clips are an easy to use, economical and patient friendly alternative to nasal packing following septal surgeries. They obtained a mean pain score of 7.23 with conventional nasal packing and 2.5 with septal clips, which is comparable to the results obtained by our study. ${ }^{1}$

Kurle et al, conducted a study and it was observed that with conventional packing, the incidence of headache was $90 \%$, and a sense of discomfort $22 \%$, which is similar to our observations. ${ }^{6}$

Dutta et al conducted a study on techniques of anterior nasal packing in epistaxis., found that $93.33 \%$ patients with gauze packing for epistaxis experienced severe pain (score $8-10$ ), whereas in our study $52 \%$ patients had a pain score over $8 .^{7}$

Schoenberg et al in their study on nasal packing after routine nasal surgery observed a mean pain score of 5.7 as compared to 1.4 in patients in whom splints were used. $^{8}$ 
Nunez et al did study on nasal packing against septal suturing, found worse pain scores in the nasal packing group than patients who underwent mucosal suturing and have concluded nasal packing is not absolutely necessary after septal surgery. ${ }^{9}$

\section{CONCLUSION}

Septal splints with clip is an effective and patient friendly alternative to conventional nasal packing in patients undergoing septoplasty, and is associated with a comfortable post-operative period when combined with bipolar cautery of inferior turbinates. However the limitation of this study is the sample size.

Funding: No funding sources

Conflict of interest: None declared

Ethical approval: The study was approved by the Institutional Ethics Committee

\section{REFERENCES}

1. Veluswamy A, Handa S, Shivaswamy S. Nasal Septal Clips: An Alternative to Nasal Packing After Septal Surgery? Indian J Otolaryngol Head Neck Surg. 2012;64(4):346-50.

2. Salinger S, Cohen DM. Surgery of the difficult septum. Arch Otolaryngol. 1955;61(4):419-21.

3. Goode RL. Magnetic intranasal splints. Arch Otolaryngol. 1982;108:319.
4. Nayak DR, Murty KD, Balakrishna R. Septal splint with wax plates. J Postgard Med. 1995;41(3):70-1.

5. Erkhan G, Ergin NT. Comparison of suture and nasal packing in rabbit noses. Laryngoscope. 2004;144:639-45.

6. Kurle G, Patil VS, Manjunath N. A comparative study between nasal clips and anterior nasal packing in septoplasty/submucosal resection patients at VIMS Bellary, Karnataka. Int J Otorhinolaryngol Head Neck Surg. 2017;3(2):364-70.

7. Dutta S, Mukherjee A, Saha J, Biswas G, Haldar D, Sen I, et al. Modified Technique of Anterior Nasal Packing: A Comparative Study Report. Indian J Otolaryngol Head Neck Surg. 2012;64(4):341-5.

8. Schoenberg M, Robinson P, Ryan R. Nasal packing after routine nasal surgery-Is it justified? J Laryngol Otol. 1993;107:902-5.

9. Nunez DA, Martin FW. An evaluation of postoperative packing in nasal septal surgery. Clin Otolargyngol. 1991;16:549-50.

Cite this article as: Pandurangarao SU, Murugendrappa MA, Jonnalagadda DK, Panicker R, Janarthanan S. A comparative study between conventional nasal packing versus nasal splint with clip after septoplasty with bilateral reduction of inferior turbinates with bipolar cautery. Int J Otorhinolaryngol Head Neck Surg 2018;4:986-9. 